\title{
Hippocrates, Galen, and the uses of trepanation in the ancient classical world
}

\author{
SYMEON Missios, M.D. \\ Division of Neurosurgery, Dartmouth-Hitchcock Medical Center, Lebanon, New Hampshire
}

\begin{abstract}
$\checkmark$ Trepanation $(\alpha v \alpha \tau \tau \eta \eta \zeta \zeta)$ is the process by which a hole is drilled into the skull, exposing the intracranial contents for either medical or mystical purposes. It represents one of the oldest surgical procedures, and its practice was widespread in many ancient cultures and several parts of the world. Trepanation was used in ancient Greece and Rome, as described in several ancient texts. Hippocrates and Galen are two of the most prominent ancient Greek medical writers, and their works have influenced the evolution of medicine and neurosurgery across the centuries. The purpose of this paper is to examine Hippocrates' and Galen's written accounts of the technique and use of trepanation in the ancient Greek and Roman world. Examination of those records reveals the ancient knowledge of neurological anatomy, physiology, and therapeutics, and illustrates the state and evolution of neurosurgery in the classical world.
\end{abstract}

(DOI: 10.3171/FOC-07/07/E11)

KEY WORDS • ancient neurosurgery - Galen - Hippocrates • trepanation •
trephination

$\mathrm{T}$ REPANATION ( $\alpha \nu \alpha \tau \tau \rho \eta \sigma \zeta)$ ) is the process by which a hole is drilled into the skull, exposing the intracranial contents for both medical and mystical purposes. The word originates from the Greek " $\tau \rho \tilde{\pi} \pi \alpha \nu$ v," which means drill, bore, or auger. ${ }^{1}$ It represents one of the oldest surgical interventions, and was certainly the first neurosurgical procedure performed by humans. The procedure itself dates back to the Mesolithic era, before the development of written language and use of metal instruments, perhaps as far back as 10,000 BC. Its practice was widespread among the continents, and evidence of trepanation has been discovered in Mesoamerica, South America, Africa, Asia, and Europe. .17,21 $^{1}$

Despite its origin in the Mesolithic era, prior to the beginning of civilization and any formal scientific-let alone medical - thinking, trepanation has been widely adopted by numerous cultures and has been refined throughout the ages. The technique evolved from the use of sharpened stones and scraping of the skull to the use of initially wooden and then metal trepans. Later, in Medieval Europe, came the use of increasingly elaborate and more sophisticated apparatuses for the less painful and safer drilling of the skull and the protection of its contents. The practice of trepanation itself also evolved from its likely ritualistic and mystical content in the primitive cultures of Africa and pre-Columbian Mesoamerica to its use by the Egyptians, Greeks, and Romans, who identified its potential therapeutic purpose, recorded their findings, and produced complicated instructions for its performance. ${ }^{11}$ Trepanation continued to be practiced throughout Medieval
Europe, based on instructions and principles of Hippocrates and Galen, until further advances in anatomy and science allowed the development of more sophisticated surgical procedures.

It is likely that the Egyptians were aware of the procedure, but they did not practice it on a regular basis. The primary written source of ancient Egyptian medical knowledge and surgical experience, the Edwin Smith Papyrusthe world's earliest known medical document, written around the 17th century BC-describes 48 battlefield injury cases, including cases of head and spine trauma. It contains the first descriptions of the cranial sutures, meninges, and cerebrospinal fluid. Imhotep, the founder of Egyptian medicine, is credited as the author of the text, although current thought is that the papyrus received contributions from multiple authors. ${ }^{1,9,19}$ It is important to note that the papyrus offered rational treatments for most of its cases in a culture in which medicine, magic, and superstition were inseparable. Nevertheless, the text does not offer specific surgical recommendations for the management of head injury by trepanation or information about the practice of neurosurgery in ancient Egypt. ${ }^{1}$

The description, use, and codification of trepanation began in Greece during the fifth century BC. Hippocrates, in his work On Injuries of the Head, described the different types of skull fractures and provided specific instructions as well as warnings about the use, and the dangers, of trepanation. ${ }^{20,32}$ The Hippocratic teachings, largely based on observation and clinical examination, were elaborated during the Roman period by Galen, who contrib- 
uted his knowledge of anatomy through his experimentation and dissections. The work of Hippocrates and Galen on the use and technique of trepanation guided its application and practice not only during the classical period but also through the Medieval era to the Renaissance.

The purpose of this paper is to present Hippocrates' and Galen's records on trepanation and to explore their teachings of its proper use, its potential dangers, and the techniques and tools employed. Their ancient descriptions of trepanation reflect the then-existing knowledge of brain anatomy and physiology, and their teachings survived through the Medieval period and influenced subsequent European scientific thinking and practice. The evolution of trepanation through its transition from ritual to a surgical procedure with therapeutic benefit parallels the evolution of ancient neurosurgery through the classical period.

\section{Hippocrates and the Teaching of Trepanation}

Hippocrates of Cos (460-377 BC; Fig. 1) lived during the "golden age of Pericles," which represents the pinnacle of ancient Greek civilization. His full name was Hippocrates Asclepiades, which means a direct descendant of Asclepios, the god of medicine, although it is unclear whether that was his real name or it was attributed to him later in life in honor. ${ }^{8} \mathrm{He}$ was an extraordinary physician, scientist, and thinker, free from the superstitions that pervaded his world. He revolutionized medicine in ancient Greece and, using the principles of observation and clinical examination, established medicine as a discipline distinct from theology and mysticism. Hippocrates led the intellectual evolution of medicine, including surgery and neurosurgery, during the classical period, and he is referred to as the "father of medicine" in recognition of his enormous contribution. He practiced at several places in ancient Greece, most likely including ancient Athens during the Peloponnesian War (431-404 BC), and is mentioned in the works of Plato, but very little information about his biography and his personal life has managed to survive through the centuries.

Despite the lack of knowledge concerning Hippocrates' life, his legacy includes a great collection of medical works, which comprise the Hippocratic corpus. The first known edition of it dates to Roman times, during the reign of the emperor Hadrian (reign 117-138 AD; Fig. 2). It is a collection of approximately 70 works, including textbooks, lectures, research notes, and philosophical essays on various subjects in medicine, in no particular order., ${ }^{3,9,15}$ The texts display no uniformity in their style of teaching or prose, and it has been recognized, even in antiquity (by Alexandrian scholars), that some works were written by persons other than Hippocrates, most likely his students. ${ }^{16}$ The corpus includes various works, most directed toward the physician and some directed more toward laymen. Some works are more theoretical and philosophical in nature, discussing professionalism in medical practice and the role of medicine as an entity distinct from religion and mysticism. None of the works are based on scientific experimentation, and only one of the books, The Sacred Disease, describes animal dissections. ${ }^{3,29}$ Human dissection was not practiced in ancient Greece, and the study of human anatomy was based on observation, external pal-

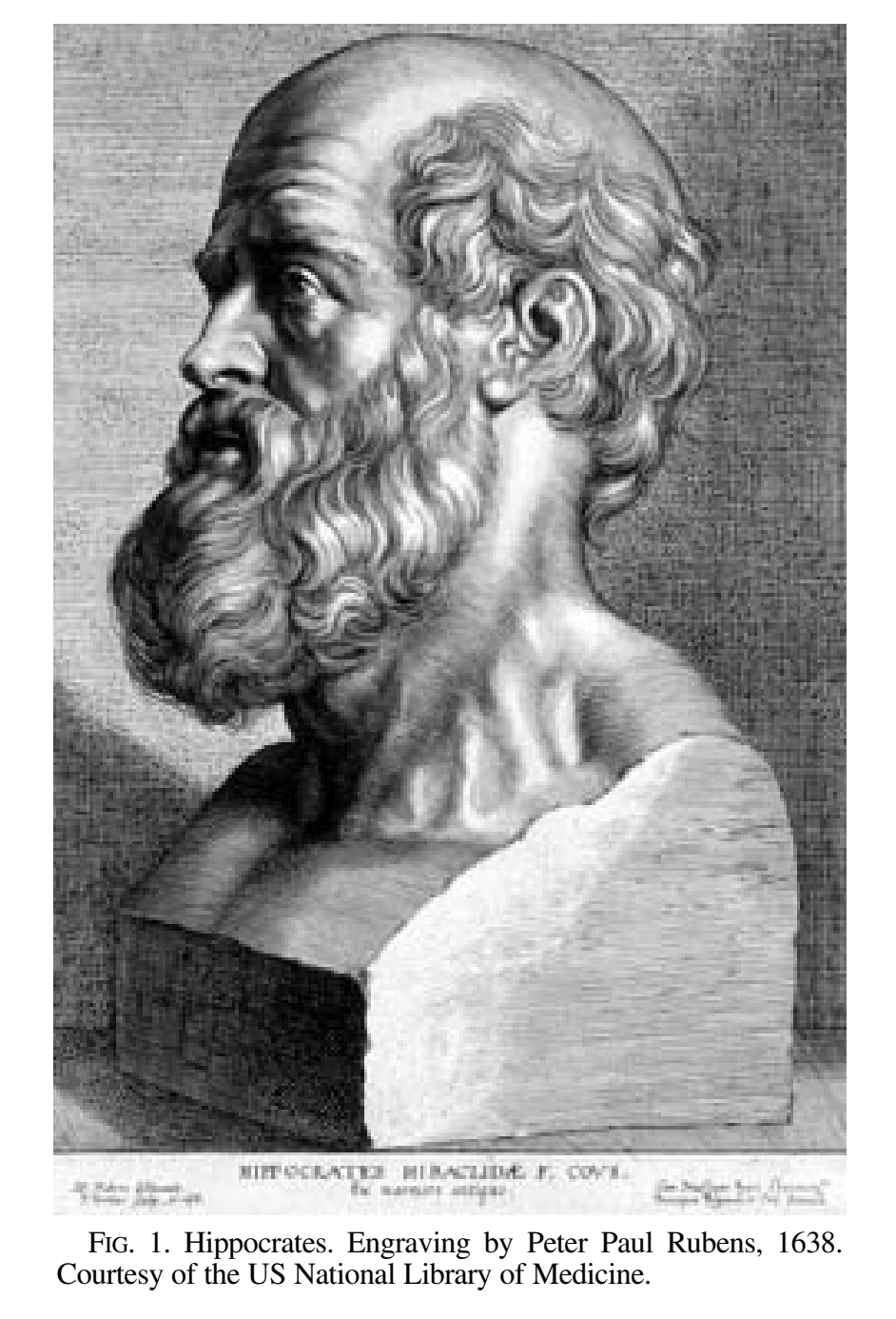

pation, and analogies derived from animal dissections. ${ }^{20}$ Nevertheless, certain recurring themes emerge among the different works of the corpus, including Hippocrates' lack of belief in cursed diseases and miraculous cures, as well as the belief that environmental factors-including hygiene, diet, and climate-have a profound influence on both mind and body. ${ }^{15}$

\section{On Injuries of the Head}

Hippocrates' greatest contribution to ancient neurosurgery is his book On Injuries of the Head, written around $400 \mathrm{BC}$. The book is a treatise on cranial anatomy and head trauma ${ }^{31}$. Using the skills of observation, documentation, and examination, the author describes the anatomy of the skull, the different types of cranial trauma and fractures, the evaluation of the patient with head injury, and management, both operative and nonoperative. Hippocrates, like all ancient Greeks, was not a stranger to head trauma and its significance, given the numerous military conflicts that burdened ancient life. As reflected in the works of Homer, Herodotus, and Thucydides, it was recognized early that head wounds were especially dangerous and that when a head lesion was sufficiently significant, death was inevitable ${ }^{7,10,14,25,26}$ 


\section{ÁIANTA TÀ TOŶ. IIIOKPATOY $\Sigma$. OMNIA OPERA
HIPPOCRATIS.}

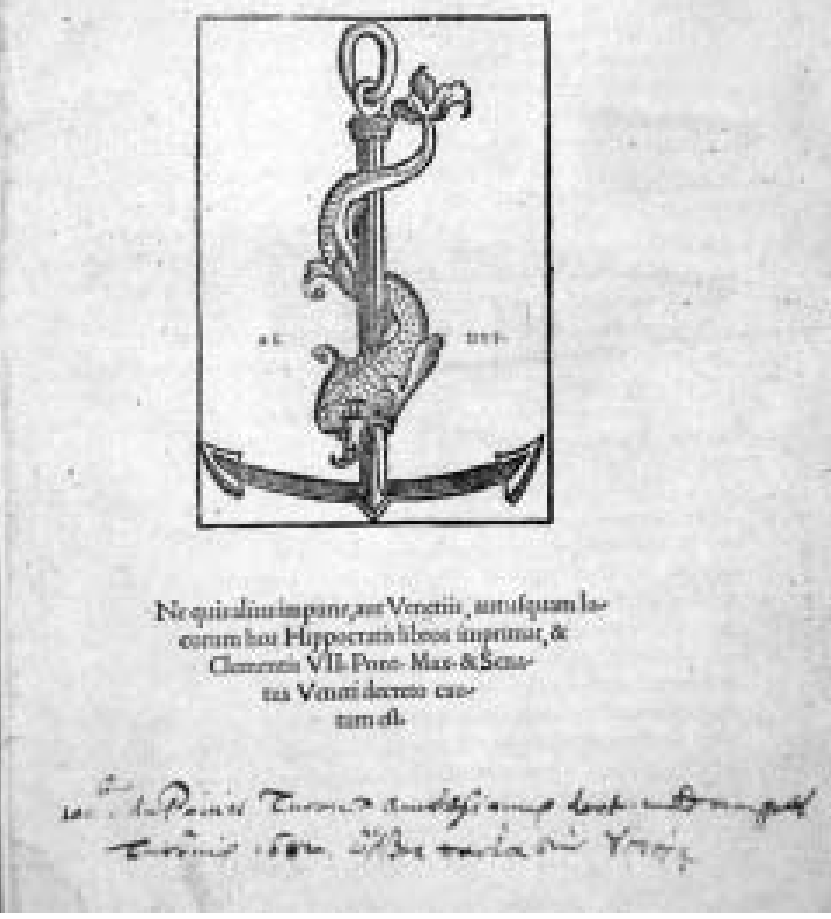

FIG. 2. Photograph of the cover of Omnia Opera Hippocratis. The first Greek edition of Hippocrates' complete works, it was printed in Venice in 1526. Courtesy of the US National Library of Medicine.

In On Injuries of the Head, Hippocrates describes five main types of traumatic head lesions and recommends appropriate management. The first type is defined as "bone contusion with a fissured fracture" and comprises injuries that result in linear skull fractures. Hippocrates describes the wide variation of these injuries and states that the fractures can vary in terms of size, thickness, distance, and degree of penetration (full or partial) through the bone. Simple "bone contusion without fracture" is the second type of head injury. The contusion may involve partial or full bone thickness, and Hippocrates accurately explains that

it is not possible to recognize any of these varieties by the

sight, so as to determine their form and extent; neither, indeed,

is it visible to the eyes when any mischief of this kind takes

place. $^{32}$

This type of injury was assumed when no fracture was seen in the cases of high-impact blunt head trauma. "Depressed skull fractures" constitute the third type of cranial trauma, and again the author describes their variability in terms of depth of depression and extent of bone involved. The fourth type of head trauma involves "dinted fractures." These occur when a weapon hits the skull and leaves an indentation on the bone, which Hippocrates calls a "hedra" ( $\varepsilon \delta \rho \alpha)$.

These injuries invariably involve bone contusion at the site of the hedra, and they are occasionally accompanied by a fracture. The size and depth of the hedra depends on the features of the weapon used and the force applied. Distinguishing these injuries from depressed skull fractures depends on the integrity of the surrounding bones, as explained by the author:

The cleft or notch which occurs in the bone, to whatever length or breadth, is a hedra, if the other bones comprehending the cleft remain in their natural position, and be not driven

inwards; for in this case it would be a depression, and no longer a hedra. ${ }^{32}$

The fifth mode of head injury involves "injuries at distant sites." Hippocrates recognized that a head injury can take place in a different part of the head from the wound and recognizes the limitations of pure observation in the prompt identification of these lesions:

For this misfortune, when it occurs, there is no remedy; for

when this mischief takes place, there is no means of ascertain-

ing by any examination whether or not it has occurred, or on what part of the head. ${ }^{32}$

Hippocrates makes a special mention of head injuries that are close to the cranial sutures or involve the sutures directly. He describes a "natural weakness" of the bone at suture lines and advises for careful observation of a hedra with a fracture near the suture line in order to determine if the fissure involves the suture itself. ${ }^{20,32}$ If it does, then the patient is likely to sustain a much greater injury and will require trepanation:

For a person wounded to the same ... extent ... will sus-

tain a much greater injury, provided he has received the blow at the sutures, than if it was elsewhere. And many of these require trepanning. ${ }^{32}$

\section{Surgical Management of Head Injuries}

Hippocrates' recommendations for surgical management of head injuries involve incision and wound exploration and trepanation. Wound incision and exploration is recommended in cases in which the bone is injured and denuded of flesh and when the wound is not large enough to allow proper inspection and determination of the presence and degree of injury. ${ }^{20}$ The incision is made proportional to the wound size in a direction selected to make "the wound of a long form." Hippocrates warns against making any incision over the temple due to potential injury to a large vessel in that region. He states that injury to that vessel will lead to contralateral convulsions of the patient. ${ }^{32}$ The vessel described probably represents the superficial temporal artery and vein, but it is unclear why the association between the vessel and the development of seizures was made. Once the incision has been made, the flesh is separated from the bone "where it is united to the membrane," probably the pericranium. Then the wound is filled with lint soaked in a "cataplasm," a mixture of boiled flour and vinegar, and left for 24 hours. ${ }^{8,20}$ The next day the wound is explored and proper assessment of the injury is made. If the injury is not readily identifiable but highly suspected, then the bone is scraped with a raspatory. If a dint or hedra is identified, then scraping the bone over the affected region is recommended. If, however, the fracture extends deep and is not likely to disappear with scraping alone, then trepanation is required. The interven- 
tion should be performed within 3 days from the initial injury and should not be delayed.

According to Hippocrates, injuries that require trepanation include cases of fissured fractures, bone contusion with or without associated fracture, and hedra injuries with associated bone contusion with or without fracture. ${ }^{32}$ Interestingly, Hippocrates recommends against trepanation in cases of depressed skull fractures and states that the depressed fractures "which are most pressed and broken require trepanning the least." Healing of those injuries involved allow the wound to granulate and the depression to rise "when flesh grows below." Injuries in proximity to the sutures are described as often requiring trepanation; the practitioner is warned against making a hole over the suture itself, but no explanation is provided. ${ }^{20}$ There is no mention of the sinuses or other vascular structures underneath the sutures. The sutures were considered points where the skull bones are weaker, and perhaps trepanation over those regions was thought to be more dangerous and to entail a higher likelihood of plunging and injuring the intracranial contents.

\section{The Technique of Trepanation}

In regard to the technique of trepanation, Hippocrates states that the bone should be sawed down until only a very thin layer remains, covering the meninges. The meninges themselves should never be exposed due to the high likelihood of subsequent infection or direct injury to them from the instrument. The thin layer of bone falls out by itself in time. Hippocrates recommends taking time to drill the hole and using water to cool down the trepan due to the heat generated from the friction of drilling. ${ }^{1,20,32}$ If, however, the physician has not followed the patient from the initial onset of trauma and substantial time has passed since the initial injury, then the cranium should be sawed down to the layer of the meninges. Hippocrates recommends using a "serrated trepan" ( $\pi \rho \imath$ óv) for this purpose and again pausing several times during the procedure and inspecting the hole with a "sound" $(\mu \eta \lambda \eta)$ a probe to assess the depth of the hole, the motility of remaining bone, and the integrity of the meninges. Any meningeal injury would predispose to infection, brain abscess formation, and death. Warnings are provided about performing trepanation in children, due to the softness and thinness of their cranium.

Wound healing following wound incision or trepanation included allowing the wound to drain and granulate. The wound was never closed but rather was packed open and allowed to granulate. Pus formation and suppuration were prerequisites for healing and were considered part of the normal healing process. ${ }^{20}$ Information is also provided for significant head injures deemed incurable or ones that were diagnosed too late. The contused or broken bone becomes necrotic and the patient develops a fever within 7 days. The wound becomes erythematous and the bone turns dark and purulent. The patient develops tongue sores and becomes delirious. Seizures may occur on the contralateral side of the injury, and patients die within 7 days in the summer or 14 days in the winter. ${ }^{32}$

\section{The Tools of Trepanation}

There are four neurosurgical tools described by Hippo- crates for the performance of trepanation. They involve two different types of bone-penetrating instruments, the trepan and the serrated trepan ( $\pi \rho \imath$ เov), which was used in cases of delayed identification of head injury that required sawing of the bone all the way down to the meninges. The "sound" $(\mu \eta \lambda \eta)$ is the probe that was used while trepanning, to determine the depth of the hole and the mobility of the underlying bone. Finally the raspatory ( $\xi \vee \sigma \tau \eta \rho)$ was used in cases in which the wound was explored and the contused bone and fracture were scraped down to the level of healthy bone. ${ }^{9,19}$

\section{Analysis of On Injuries of the Head}

Contemporary historical analysis of the treatise $O n$ Injuries of the Head has raised several arguments regarding the use of trepanation in ancient Greece as well as the identity of the treatise's author and his personal expertise in the procedure. It is known that several of the works included in the Hippocratic corpus were actually written by authors other than Hippocrates, and there are arguments that support the notion that On Injuries of the Head represents one of these works. ${ }^{16}$ Regardless of its authorship, the book appears to have been written by an experienced surgeon of the time, whose description about the use and technique of trepanation, however, leaves several questions unanswered.

The author recommends trepanation for a wide variety of head injuries, to be performed within the first 3 days after injury, but the precise reason for trepanning is never explicitly stated. There is no mention of trepanning in order to drain an underlying hematoma or whether trepanation was used as a means to protect against the development of a brain abscess. Similarly, trepanation is not recommended for the repair of depressed skull fractures and the removal of necrotic bone fragments, and these injuries are allowed to heal by granulation. The technique of allowing a thin layer of bone over the hole is strangely hesitant and constitutes a source of speculation that the author was not personally experienced in trepanation. ${ }^{16}$ This technique was not recommended by later practitioners of trepanation, who proposed the complete removal of bone to the level of the meninges.

At the time On Injuries of the Head was written, trepanation was commonly practiced in Europe among the Celts, whose territory spread from France along the Danube to the Black Sea. ${ }^{16}$ The majority of findings indicate that the Celts employed the more traditional scraping technique of trepanation, but a minority of Celtic settlements along the southern Viennese basin adopted the practice of drill trepanations. ${ }^{1}$ These settlements were located along the amber trade route from Western Europe to the Mediterranean and were the sites of cultural exchange between the Celtic and Greek worlds. ${ }^{1}$ It is possible that the author of the treatise had some exposure to Celtic tradition and trepanation practices, which influenced his writing. The importance of the book On Injuries of the Head is that it represents the first historically recorded account of the use of trepanation in ancient Greece and reflects the transition of the practice from Western Europe to the Mediterranean and its use, as a neurosurgical procedure, for strictly therapeutic rather than mystical purposes. In subsequent medical texts, specifically Epidemics $I V$ and Epidemics $V$, 


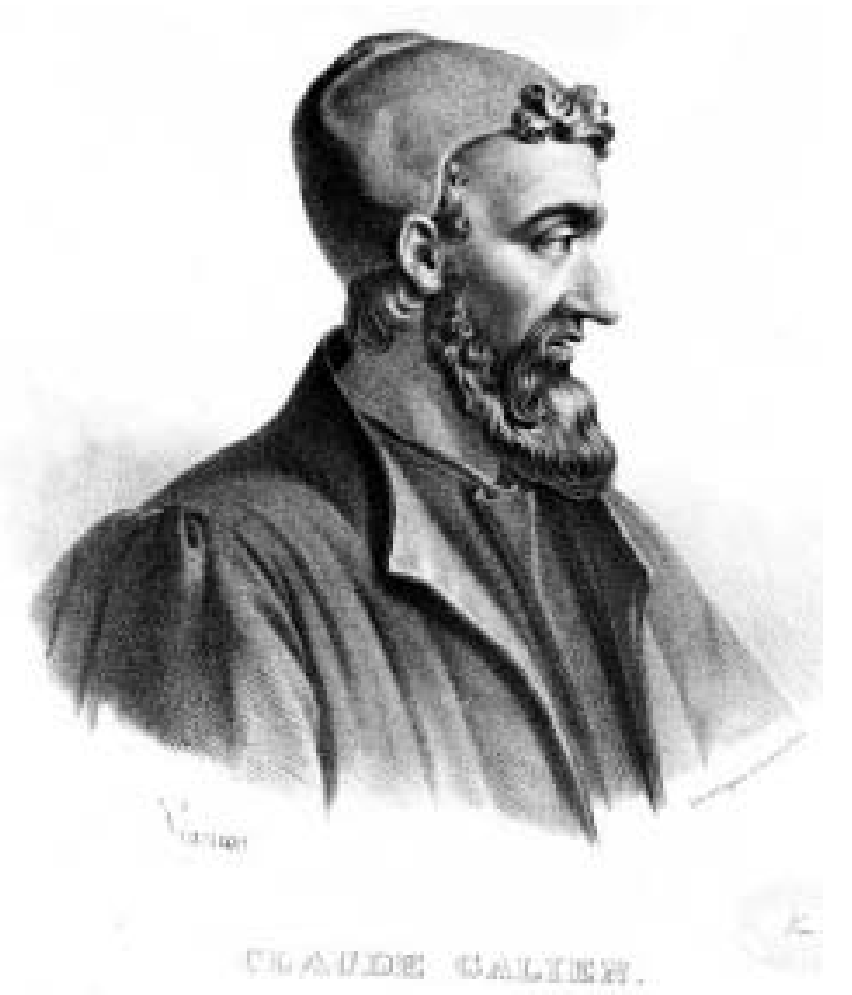

FIG. 3. Galen. Lithograph by Pierre Roche Vigneron (Paris: Lith de Gregoire et Deneux, ca. 1865). Courtesy of the US National Library of Medicine.

written approximately 70 years later, cases treated by trepanation are described; the recommendations for its use are expanded to include elevation of depressed skull fractures, drainage of intracranial abscesses, and removal of necrotic bone; several new surgical instruments are also introduced.

Early fourth-century classical surgeons were probably hesitant to perform early trepanation, and little evidence of trepanned skulls has been discovered, given the presumed frequency of head trauma in ancient Greece. ${ }^{10,12}$ However, literary evidence proves that trepanation was a procedure known to Hippocratic physicians and that it was becoming more common over the years, although it was often used as a last resort. The contributions of Hippocrates and his contemporaries and the intellectual environment of Ancient Greece allowed trepanation, and with it ancient neurosurgery, to evolve from an ancient, oral, disorganized, and mystical tradition that was likely Celtic in origin, to a written, scientific, and systematic topic of study, devoid of superstitions and religious influences.

\section{Galen and the Teaching of Trepanation}

Six centuries after the birth of Hippocrates, the evolution of ancient medicine and neurosurgery reached another milestone with the studies and writings of Galen of Pergamon (AD 129-200; Fig. 3). Galen, whose name in Greek ( $\Gamma \alpha \lambda \eta \nu$ ó $\varsigma)$ means "peaceful," was born in the city of Pergamon in Asia Minor (now Turkey). His father, Aelius Nicon, was an architect and a scholar, with interests in mathematics, astronomy, philosophy, and Greek literature. Galen grew up in an environment of intellectual stimulation and strong scholarly tradition, at a time when the Hellenic element was becoming increasingly strong within the Roman world and Greek aspects of learning and the Greek language were being used more extensively. ${ }^{22}$

According to legend, the gods instructed Nicon to urge his son to study medicine, and for 4 years Galen studied at the Aesculapion of Pergamon, a sanctuary to the god of healing and a site where medical knowledge and religious activities, healing, and superstition blended. ${ }^{24}$ After his father's death in $150 \mathrm{AD}$, Galen traveled to Smyrna, Corinth, and Alexandria. He spent 4 years at the Alexandrian school of medicine, where he studied anatomy and physiology and was exposed to the tradition of Herophilus and Erasistratus. He returned to Pergamon in $157 \mathrm{AD}$, at the age of 28 , and began to practice medicine as a physician appointed to the gladiators. The gladiators' injuries provided Galen with ample opportunities to expand his knowledge of anatomy, physiology, and treatment, to gain valuable practical experience in trauma, and thereby to produce some of his most original work.

In $163 \mathrm{AD}$, Galen moved to Rome, where his work, anatomical studies, passion for knowledge, and success as a physician quickly distinguished him from the established authority of Roman physicians. In 168 AD, Galen joined the emperor Marcus Aurelius, and in 169 AD he was appointed personal physician to Commodus, the emperor's son. Under the protection of the Roman Empire, Galen continued his studies, teachings, and writings. In 191 AD, a fire destroyed important parts of Galen's work, but he was not dissuaded, and he spent the next few years of his life, until his death in $200 \mathrm{AD}$, continuing his medical research and writings and producing major works. ${ }^{25}$

\section{The Works and Philosophy of Galen}

Galen's works included over 500 lectures, books, and treatises, written in Attic Greek and totaling more than 4 million words. ${ }^{8,24,28}$ Unfortunately, due to the fire of 191 , only a sample has survived across the centuries. His works encompass every aspect of medicine and describe important advances in anatomy, physiology, and treatment. His contribution to our knowledge of the nervous system, neuroanatomy, and neurosurgery is vast. Galen described the corpus callosum, ventricular system, fornix, tectum, pineal and pituitary glands, and the cranial nerves. ${ }^{8,24,27} \mathrm{He}$ identified the recurrent laryngeal nerve in animals and recognized its association with voice changes. ${ }^{8} \mathrm{He}$ recognized that spinal trauma can affect the use of limbs and described the peripheral nervous system and its relationship to the spinal cord. Studies of the ventricular system allowed him to recognize and describe the symptoms and signs of hydrocephalus. ${ }^{8,23,30} \mathrm{He}$ improved the technique of trepanation and defined its use, which became more widespread. Galen's work, based on the foundations of the Hippocratic corpus, collected all preceding medical knowledge, developed it, expanded on it, and shaped the practice of medicine for the centuries to come.

The quest for intellectual supremacy within a rigid system of logic, reason, and experience dominates Galen's teachings. Galen never disputed the works of Hippocrates and was respectful of the legacy of the knowledge passed on by his predecessors, yet he admitted that they were at 


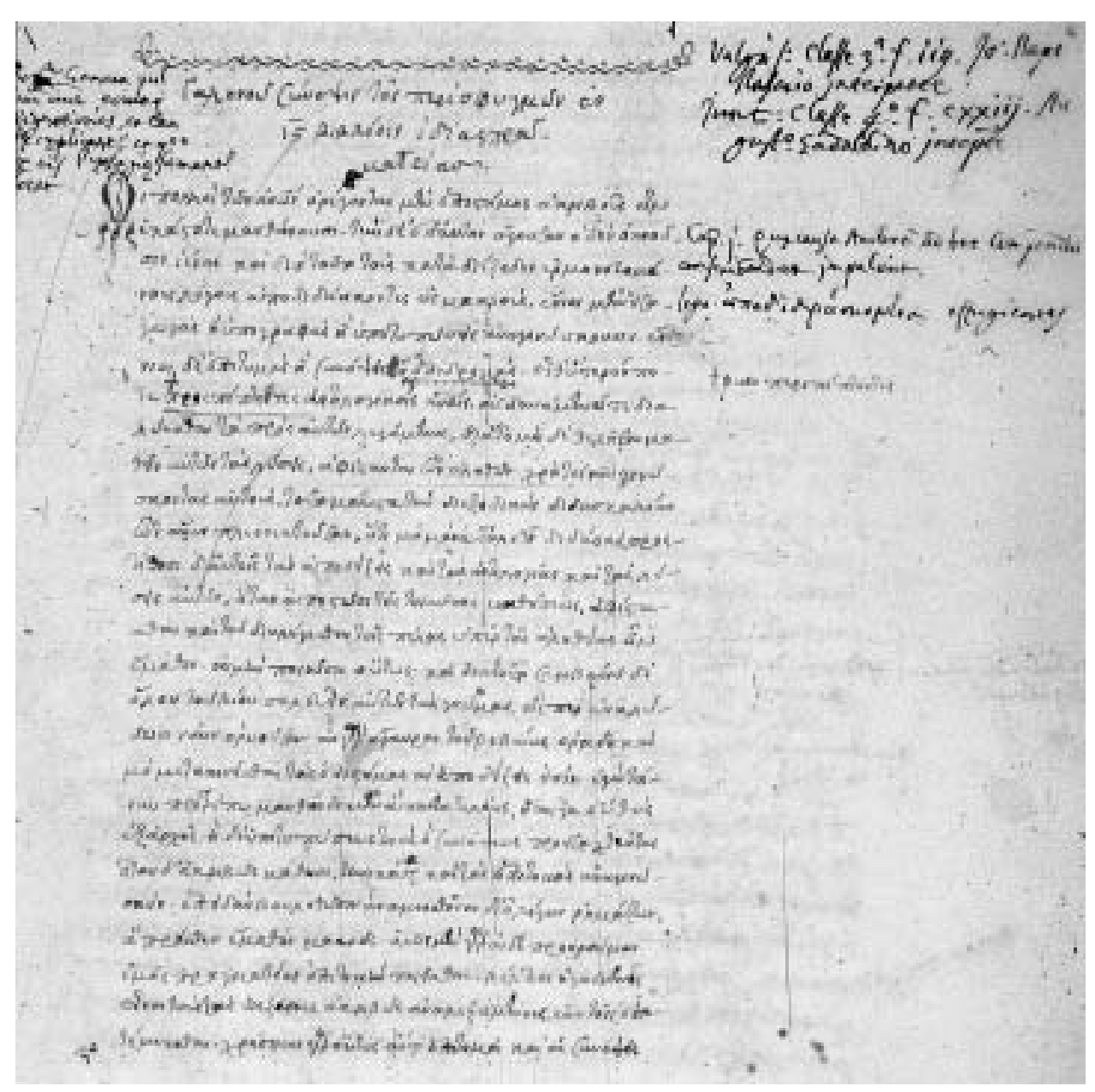

FIG. 4. Photograph of the first page of Synopsis de Pulsibus (Venice, ca. 1550), the Greek manuscript of Galen's treatise on the pulse, interleaved with a Latin translation. Courtesy of the US National Library of Medicine.

times obscure and that the knowledge should be used as a foundation for future scientific discovery only. ${ }^{24}$ Galen was exposed to various medical sects and was intolerant of several of his colleagues because of their ignorance and superficial knowledge of medicine. ${ }^{5}$ Galen advocated philosophical training for all physicians and the use of proven principles and logical progression in the gain of new medical knowledge, the same way a mathematician uses proven theorems to advance his field. Through his experiments and dissections, Galen sought to demonstrate the workings of the human body in an indisputable and undeniable way. He stressed the importance of anatomical knowledge for practicing surgeons: ${ }^{2}$

If a man is ignorant of the position of a vital nerve, muscle, artery or important vein, he is more likely to maim his patients or to destroy rather than save life. ${ }^{30}$

Galen's work on both the science and the philosophy of medicine ushered medicine and neurosurgery through the classical period, and his writings served as the basis of knowledge regarding the nervous system through the Renaissance until the end of the 16th century.

\section{Galen's Teaching on Trepanation}

Galen lived in an era when trepanation was better known and more accepted by the practicing physicians as well as the public. He advocated use of the procedure for relief of intracranial pressure and drainage of phlegmatous lesions. ${ }^{22}$ Galen was aware of and accepted Hippocrates' description of head trauma and the classification of the five different types of head injuries. The treatise On Injuries of the Head is mentioned in three of the surviving works of Galen: De methodo medendi libri, In Hippocratis librum de officina medici commentarii, and In Hippocratis librum primum epidemiarum. ${ }^{24}$ The traditional teaching of protecting the meninges persists, and Galen describes the importance of safeguarding the dura and protecting its integrity. Galen's works describe the technique and tools of trepanation and the use of the procedure for both clinical and research purposes. ${ }^{22}$

Trepanation is used in clinical practice for the relief of intracranial hematomas in the case of head trauma, as well as the drainage of "phlegmatous" lesions of the head. ${ }^{22}$ Its use is also expanded to include the repair of depressed skull fractures. The patients typically sat up in order to allow blood to drain and to prevent obstruction of the surgical field, which was important in a time without suction and proper lighting. Hemostasis was an important issue, particularly because the scalp is so well vascularized. The 
incision was intended to suppurate, drain, and then heal slowly, and the wound was designed to be left open and heal by secondary intention and never by tight packing. ${ }^{1}$

Several substances were applied to scalp incisions and trepanation wounds for both hemostatic and medicinal purposes. Most of these substances acted as chemical irritants, and their application created a local inflammatory reaction and osteitis, which can be identified on skull remains as erosion of the bone along the trepanation site. Nevertheless, sometimes application of these chemical irritants also served an antiseptic purpose because they impeded bacterial growth as well. ${ }^{1}$ Hippocrates advised application of a "jet-black ointment" of unknown consistency, followed by application of an oil-smeared linen rag and then linen soaked in cataplasm (a boiled mixture of flour and vinegar) in wounds in which the degree of bone damage cannot be determined. Galen described application of mixtures of vinegar, honey, and sea salt in rain water as well as ointments, which included medicinal plant extracts, pigeon blood, and black coral powder. ${ }^{13}$

The danger of injury to the meninges from free bone fragments is identified, and trepanation and wound exploration and removal of bony fragments become the treatment for such injuries. Galen advises all physicians to apply their knowledge and practice their surgical skills first on animals. For surgical practice, he recommends using heads of animals that are most similar to humans, such as apes, and for the study of anatomy, animals with large brains and easily identifiable structures, such as oxen. ${ }^{22,24}$ He discusses the importance of minimizing blood loss and protecting the dura, and he states that the only way to gain proficiency is through knowledge of anatomy, repetition, experimentation, and practice. Galen's descriptions of the procedure reveal that he had extensive personal experience and was highly skilled in its practice. He was familiar with the dangers associated with the procedure and the effects of too much pressure on the exposed brain. In $D e$ locis affectis he states:

If one presses too hard while treating the fractured bones of the skull by trepanation, the patients immediately lose all sensation and becomes motionless. 22,24

\section{And in De placitis Hippocratis et Platonis:}

For when we chisel out the fragments of bone we are compelled for safety to put underneath the so-called protectors of the meninx, and if these are pressed too heavily on the brain, the effect is to render the person senseless as well as incapable of all voluntary motion. ${ }^{24}$

The effect of such an injury is, however, often attributed not to brain parenchymal damage, but to pressure on the ventricular system, an assumption Galen made based on his vivisection experience..$^{24,30}$

Galen himself performed numerous dissections and often employed trepanation for research purposes during his vivisections and study of the brain in vivo. In his work $\mathrm{On}$ Anatomical Procedures he describes one of his vivisections:

Insert a hook into the dura mater and draw it upwards. Then first cut through the piece of it that has been raised, so that it may not make contact with the part of the brain lying underneath it. ... Should the dissection be thus performed, then after you have laid open the brain and divested it of the dura mater, you can first of all press down upon the brain on each one of its four ventricles, and observe what derangements have afflicted the animal.... And when one presses down upon that ventricle which is found in the part of the brain lying at the nape of the neck, then the animal falls into a very heavy and pronounced stupor. ... And if the incision should have been imposed upon the fourth ... ventricle then the animal seldom returns to its natural condition. . $^{4,23,27}$

Comparing the effects of different ventricular lesions, he states that

incising the posterior ventricle harms the animal the most, and next after that the middle ventricle. Incising each of the anterior ventricles causes a less serious injury, but of greater degree in older animals, a lesser degree in the young. ${ }^{22,27}$

He accurately observes that compression of the brain and the ventricles leads to mental status changes and stupor, which are reversible with time, and that injuring the ventricles, particularly the fourth ventricle ("the posterior ventricle"), leads to more severe and irreversible mental status depression and coma.

\section{Tools of Trepanation}

In Galen's time, many more instruments had been added to the physicians' armamentarium, and the technique of trepanation had become more sophisticated. Galen describes the use of various trepans, some of which are guarded drills designed to minimize the danger of dural injury. The "crown trephine" ( $\chi$ olvıkí $\varsigma$ ) lacked a guard and was used for removing bone and gaining intracranial access. The "drill trepan" ( $\tau \rho \tilde{\delta} \pi \alpha \nu \nu)$ was used in a technique of making multiple perforations on the bone in a circumferential fashion in order to facilitate bone removal. A guarded drill version of that instrument was also used and was termed the abaptiston ( $\alpha \beta \alpha$ '́ $\tau \tau \iota \sigma \tau o v)$. The guarding mechanism often involved a way to set the length of the drill prior to the procedure. Galen also describes the use of the meningophylax $(\mu \eta v i \gamma \gamma о \varphi v \lambda \alpha \xi)$, the "dural protector," a flat piece of metal that was passed through fracture fissures under the bone and over the dura and served as another layer of protection. ${ }^{18,22}$ Specifically for the repair of skull fractures, Galen preferred using a chisel to remove the bone around the fracture and recommends against the use of a trepan, which he considers a practice of the "ancients."

All kinds of fractures of the skull are treated by chiseling out the fractured parts, cutting clear round the fracture with the chisel. The ancients used to cut them out with circular trephines which they rotated, later head augurs were employed, which gave starting points for the chisels. For the moderns the chisels alluded to above suffice. . $^{6,30}$

\section{Galen's Study of Hydrocephalus}

Galen was a pioneer in the study of hydrocephalus. He described cases of the condition, classified different types of hydrocephalus according to the anatomical compartments he considered affected, and offered recommendations for surgical treatment. In his work Introductio seu Medicus he writes:

There are four kinds of hydrocephalus, one between the brain and the meninges, one between the membranes and the bone, one between the bone and the pericranium and one between the bone and the skin. In the skin occur favus (a dermatophyte skin infection), wens (sebaceous cysts), and on the outside, baldness. For favus or wens we make either a straight or curved incision on the surface, and pull out the sac with the fingers and remove them with the fluid contained in them. 
Hydrocephalus under the skin and pericranium we empty by two or three incisions. Those beneath the bone we chisel out. Those between the meninges and the brain do not admit treatment. ${ }^{6,30}$

A case that illustrates the use of trepanation for the treatment of hydrocephalus involves the 1995 discovery on the site of the ancient town of Fidenae (along the suburbs of Rome) of the skeleton of a child who had hydrocephalus described by Mariani-Constantini et al. ${ }^{13}$ The cranium had been well preserved and bore the mark of a $5 \times 5-\mathrm{cm}$ trepanation orifice along the frontoparietal region. There was evidence that a blunt surgical instrument was used, most likely a chisel, and the borders of the orifice displayed the evidence of osteitis following the procedure. ${ }^{13}$ Further analysis of the skull and the location of indentations and vascular grooves suggests evidence of chronic shift of the intracranial contents, probably the result of a supratentorial mass. Most likely the child was afflicted by a brain tumor, which led to hydrocephalus and the development of macrocephalic features. The trepanation would have been performed in order to relieve symptoms associated with the increased intracranial pressure. The skull markings indicate that the procedure was done while the child was alive and that the child lived for a few weeks after the procedure. ${ }^{13}$

\section{Conclusions}

Trepanation was a well-established procedure during the ancient classical period and represents one of the earliest neurosurgical interventions performed. The works of Hippocrates and Galen helped to usher this procedure out of a world of mysticism and superstition and into the world of scientific thought, anatomical study, and therapeutics. The study of the works of Hippocrates and Galen allows us to follow the evolution of this technique through the centuries. The first recordings of trepanation in the Hippocratic corpus represent the introduction of this practice to the Greeks and their first, hesitant attempts at using it, while Galen's teachings reveal a higher degree of experience, skill, and comfort with the procedure, as well as anatomical knowledge resulting from the five additional centuries of experimentation since Hippocrates. The principles of ancient neurosurgery and trepanation were applied in medieval Europe, just as they were in Galen's time, until the time of Vesalius. The works of Hippocrates and Galen inspired thousands of physicians throughout Europe, and their teachings established the field of neurosurgery in the classical world and laid the foundation for medical and neurosurgical practice for the next 1500 years.

\section{References}

1. Arnott R, Finger S, Smith C (eds): Trepanation: HistoryDiscovery-Theory. Lisse, The Netherlands: Swets \& Zeitlinger Publishers, 2003

2. Awad IA: Galen's anecdote of the fallen sophist: on the certainty of science through anatomy. J Neurosurg 83:929-932, 1995

3. Chadwick J (tr), Lloyd GER (ed): Hippocratic Writings. London: Clays Ltd, 1984

4. Duckworth WLH (transl), Lyons MC, Towers B (ed): Galen
On Anatomical Procedures: Translation of the Surviving Books with Introduction and Notes. Oxford: Oxford University Press, 1998

5. Frede M, Walzer R (transl): Galen. Three Treatises on the Nature of Science. Indianapolis: Hackett Publishing Company, 1985

6. Galen. Introductio seu medicus. Kuhn CG. Claudii Galeni Opera Omnia, vol. 14. Hildesheim: Olms, 1965, pp 674-797

7. Goodrich JT: History of spine surgery in the ancient and medieval worlds. Neurosurg Focus 16(1): E2, 2004

8. Goodrich JT: Neurosurgery in the ancient and medieval worlds, in Greenblatt SH, Dagi TF, Epstein MH (eds): A History of Neurosurgery: in Its Scientific and Cultural Contexts. Park Ridge, Ill: AANS, 1997, pp 37-64

9. Greenblatt SH, Dagi F, Epstein MH (eds): A History of Neurosurgery: in Its Scientific and Cultural Contexts. Park Ridge, Ill: AANS, 1997

10. Grmek MD, Muellner M, Muellner L (transl): Diseases in the Ancient Greek World. Baltimore: Johns Hopkins University Press, 1989

11. Gross CG: Trepanation from the Palaeolithic to the internet, in Arnott R, Finger S, Smith C (eds): Trepanation: HistoryDiscovery-Theory. Lisse, The Netherlands: Swets \& Zeitlinger Publishers, 2003, pp 307-322

12. Majno G: The Healing Hand: Man and Wound in the Ancient World. Cambridge: Harvard University Press, 1975

13. Mariani-Constantini R, Catalano P, di Gennaro F, di Tota G, Angeletti LR: New light on cranial surgery in ancient Rome. Lancet 355:305-307, 2000

14. Marketos SG, Skiadas PK: Hippocrates. The father of spine surgery. Spine 24:1381-1387, 1999

15. Marketos SG, Skiadas PK: The modern hippocratic tradition. Some messages for contemporary medicine. Spine 24: 1159-1163, 1999

16. Martin G: Was Hippocrates a beginner at trepanning and where did he learn? J Clin Neurosci 7:500-502, 2000

17. Martin GT: Trepanation in the South Pacific. J Clin Neurosci 2:257-264, 1990

18. Milne JS: Surgical Instruments in Greek and Roman Times. Oxford: Clarendon Press, 1907

19. Nunn JF: Ancient Egyptian Medicine. Norman: University of Oklahoma Press, 1996

20. Panourias IG, Skiadas PK, Sakas DE, Marketos SG: Hippocrates: a pioneer in the treatment of head injuries. Neurosurgery 57:181-189, 2005

21. Rifkinson-Mann S: Cranial surgery in ancient Peru. Neurosurgery 23:411-416, 1988

22. Rocca J: Galen and the uses of trepanation, in Arnott R, Finger S, Smith C (eds): Trepanation: History-DiscoveryTheory. Lisse, The Netherlands: Swets \& Zeitlinger Publishers, 2003, pp 253-271

23. Rocca J: Galen and the ventricular system. J Hist Neurosci 6: 227-239, 1997

24. Rocca J: Galen on the Brain: Anatomical Knowledge and Physiological Speculation in the Second Century AD. Leiden, the Netherlands: Brill Academic Publishers, 2003

25. Sahlas DJ: Functional neuroanatomy in the pre-Hippocratic era: observations from the Iliad of Homer. Neurosurgery 48: 1352-1357, 2001

26. Sanan A, Rengachary SS: The history of spinal biomechanics. Neurosurgery 39:657-669, 1996

27. Singer C (transl, ed): Galen. On Anatomical Procedures. Oxford: Wellcome Historical Medical Museum, 1956

28. Singer PN: Galen: Selected Works: Translated with an Introduction and Notes. Oxford: Oxford University Press, 1997

29. Temkin O: The Falling Sickness: A History of Epilepsy from the Greeks to the Beginnings of Modern Neurology, ed 2. Baltimore: Johns Hopkins, 1971 
30. Toledo-Pereyra LH: Galen's contribution to surgery. J Hist Med Allied Sci 28:357-375, 1973

31. Viale GL, Deseri SE, Gennaro S, Sehrbundt E: A craniocerebral infectious disease: case report on the traces of Hippocrates. Neurosurgery 50:1376-1379, 2002

32. Withington ET (transl): Hippocrates, Volume III: On Wounds in the Head. (Loeb Classical Library, No. 149.) Harvard University Press: Loeb Classical Library, 1928
Manuscript submitted April 23, 2007.

Accepted May 30, 2007.

Address reprint requests to: Symeon Missios, M.D., DartmouthHitchcock Medical Center, Section of Neurosurgery, One Medical Center Drive, Lebanon, New Hampshire, 03756. email: Symeon. Missios@hitchcock.org. 